Does Leader Humor Style Matter and to Whom

\title{
Pedro Neves
}

Nova School of Business and Economics, Universidade Nova de Lisboa, Portugal Gokhan Karagonlar

Dokuz Eylül University, School of Business, Turkey

Author Note

This work was funded by National Funds through FCT - Fundação para a Ciência e Tecnologia under the project Ref. UID/ECO/00124/2013 and by POR Lisboa under the project LISBOA-01-0145-FEDER-007722.

Correspondence concerning this article should be addressed to Pedro Neves, Nova School of Business and Economics, Campus de Carcavelos, Rua da Holanda, n.1, 2775-405 Carcavelos, Portugal. E-mail: pneves@novasbe.pt 
Pedro Neves is an Associate Professor at Nova School of Business and Economics and is currently the Director of the PhD in Management program. He has published in journals such as Journal of Applied Psychology, Journal of Occupational and Organizational Psychology, and The Leadership Quarterly. His research interests focus on leadership and interpersonal relationships in the workplace, change management, and entrepreneurship.

Gökhan Karagonlar is an Associate Professor at the Department of Business Administration of Dokuz Eylül Üniversity. He has published in journals such as Journal of Applied Psychology, Journal of Organizational Behavior and Organizational Behavior and Human Decision Processes. His main research interests are employee-organization relationships, leadership and motivation, and cooperation in social dilemmas. 


\begin{abstract}
Purpose: The interest on leader humor styles is recent. By applying a trustworthiness framework, we examine a) how leader humor styles contribute to performance and deviance via trust in the supervisor and b) who benefits/suffers the most from different leader humor styles.
\end{abstract}

Methodology: We tested our hypotheses in a sample of 428 employee-supervisor dyads from 19 organizations operating in the services sector.

Findings: Affiliative and self-enhancing leader humor styles are particularly beneficial for employees with low core-self-evaluations, helping them develop trust in the supervisor and consequently improving their performance. An aggressive leader humor style, via decreased trust in the supervisor, reduces performance, regardless of employees' core self-evaluations. Self-enhancing and self-defeating leader humor styles also present significant relationships with organizational deviance.

Research limitations: Limitations include the cross-sectional design and the limited number of mechanisms examined.

Practical implications: Organizations need to train leaders in the use of humor and develop a culture where beneficial humor styles are endorsed, while detrimental humor styles are not tolerated.

Originality: These findings contribute to the literatures on trust and humor, by showing that the use of humor is not as trivial as one could initially think, particularly for those with low core self-evaluations, and by expanding our knowledge of the mechanisms by which different leader humor styles may influence performance and deviance.

Keywords: Leader humor styles, core self-evaluations, trust, performance, deviance. 


\section{Does Leader Humor Style Matter and to Whom}

Humor is a basic element of human interaction and is part of the culture of many successful companies (Romero and Cruthirds, 2006). Increasing evidence demonstrates the benefit of using positive humor in the workplace (Mesmer-Magnus et al., 2012), particularly by leaders. Leader humor contributes to the quality of the leader-member exchange (e.g., Pundt and Herrmann, 2015; Pundt and Venz, 2017), affective organizational commitment (Pundt and Venz, 2017), burnout and strain (Huo et al., 2012; Pundt and Venz, 2017), innovative behavior (Pundt, 2015), and performance (Avolio et al., 1999; Kim et al., 2016).

Most studies focus on the positive effects of leader humor. Nonetheless, its detrimental consequences, if misplaced or used poorly, have also been documented, albeit more rarely (e.g., Huo et al., 2012; Kim et al., 2016; Pundt and Herrmann, 2015; Robert et al., 2016; Tremblay, 2017; Wisse and Rietzschel, 2014). A closer look into these studies also shows a concern to identify boundary conditions, as the effects of humor seem to depend on several other elements (Huo et al., 2012; Kim et al., 2016; Robert et al., 2016; Tremblay, 2017; Wisse and Rietzschel, 2014).

Thus, several important questions remain unanswered. First, building on a trust framework (Mayer et al., 1995) embedded in social exchange theory (Blau, 1964), we argue that different supervisor humor styles (Martin et al., 2003), contribute to the supervisor's image of trustworthiness. Leader humor styles signal (lack of) trustworthiness (Karakowsky et al., 2019), influencing the quality of social exchange. A more nuanced perspective is warranted in order to understand how humor, in its multiple facets, contributes to the social exchange process. We focus on humor because, as Robert and Yan (2007) suggested, "although humor might appear to be inconsistent with the serious nature of work, it inserts itself in some form in most social contexts (...) and plays an important role in regulating social behavior in all societies (...)" (p.206). 
Second, we still need to understand who benefits and/or suffers the most from the use of humor by leaders, as the effect of humor depends not only on the person using it, but on the perceiver as well (Wisse and Riezschel, 2014). Moreover, we know that individuals react differently to the underlying norms of social exchanges (Cropanzano \& Mitchell, 2005). By proposing employee core self-evaluations (CSE; Judge and Bono, 2001) as a boundary condition concerning how employees react to the supervisor's humor styles, we contribute to both the social exchange and humor frameworks.

Third, we still know little about how leader humor influences employee behavior. The few studies that examine the relationship between humor and performance present mixed results (Avolio et al., 1999; Goswami et al., 2016; Kim et al., 2016), suggesting that the relationship might not be direct, but via several mechanisms (Cooper, 2008). Additionally, the link between humor and deviance has remained elusive in the literature, despite the awareness of the pervasiveness and costs of deviant behaviors (Bennett and Robinson, 2000). We explore a fundamental social exchange mechanism, trust in the supervisor, in order to shed light onto why individuals react to leader humor. We include performance and deviance as two proactive attempts to either help or undermine organizational goals (Rotundo \& Sackett, 2002).

\section{Leader Humor Styles and Trust}

The seminal discussions around humor conceptualized it as a social lubricant. However, humor might not always facilitate social relationships; it might actually undermine them. To provide a more comprehensive view of humor, Martin et al. (2003) developed the Humor Styles framework. The framework revolves around two axes: whether humor is used to enhance the self or one's relationship with others; and whether humor is benign and benevolent or potentially detrimental or injurious. Thus, humor can be: affiliative (to enhance the relationship with others in a benign fashion); self-enhancing (to enhance the self in a 
benevolent fashion); aggressive (to enhance the self in a detrimental fashion to others); and last, self-defeating (to enhance the relationship with others at the expense of oneself) (Martin et al., 2003). Individuals express each humor style in particular ways: telling jokes and saying funny things (affiliative); enjoying the incongruities of life even in the face of stress (selfenhancing); putting down others and ridiculing them (aggressive); or saying funny things to gain approval while ridiculing oneself (self-defeating). Researchers should examine the four styles independently. Martin et al.'s (2003) discriminant validity analysis and Robert et al.'s (2016) findings support the importance of a more nuanced view of humor and highlight its role in the maintenance of social exchanges.

Trust is another important cornerstone of social relationships. Only social exchanges tend to engender feelings of personal obligation, gratitude, and trust (Blau, 1964). Mayer et al. (1995) defined trust as the willingness to put oneself in a position of vulnerability to the actions of another party based on the expectation that the other will behave with one's interests in mind. Employees observe the nature, actions and practices of their leaders to draw inferences about the nature of their relationship, which in turn solidifies or destroys trust in leadership (Dirks and Ferrin, 2002). Mayer et al.'s (1995) model of trust emphasizes the importance of trustworthiness as an indication of the character of the trustee. Trustworthiness is built around three characteristics of the trustee: ability (skills that enable a party to be influential in a given domain), benevolence (if the person is believed to want to genuinely do good to the trustor), and integrity (the trustee follows a set of principles that the trustor finds acceptable).

Karakowsky et al. (2019) examined affiliative humor and argued that it influences trust in the leader by signaling two of these qualities. Affiliative humor signals benevolence because it reflects humility (Gkorezis \& Bellou, 2016) and reduces status differences between leaders and their teams. It also signals ability (or at least self-confidence) as a poor performer 
would not feel comfortable engaging in activities often seen as frivolous in the workplace. We argue that affiliative humor also demonstrates integrity, as the leader is using humor to enhance interpersonal cohesiveness and attraction (Martin et al., 2003), behaving in a way that is consistent with positive organizational values.

A similar reasoning can be applied to the other three humor styles. Like affiliative humor, self-enhancing humor should also reflect ability given its positive valuation of the self and high self-confidence. Even though it has an intrapersonal focus and is a healthy defense mechanism (Martin et al., 2003), self-enhancing humor should also signal benevolence as it emphasizes the maintenance of a positive outlook, particularly in the face of adversity, and integrity given that it is a demonstration of tolerance and is not detrimental to others. Aggressive and self-defeating humor should signal the opposite; that the leader is not trustworthy. Aggressive humor not only signals a lack of benevolence, as the leader tries to enhance the self at the expense of others, but it also indicates that the leader lacks integrity (reflected in putting others down or using humor to manipulate others; Martin et al., 2003) and competence (as making jokes at the expense of others can be interpreted as a strategy to pass the blame to others). Self-defeating humor should primarily be interpreted by trustors as compensating for lack of ability (or self-confidence). It may also signal to subordinates that the leader may not have the capability and resources to look after their interests.

Building on social exchange theory, and particularly the trust framework, we argue that employees will trust their supervisors to the extent that they signal their trustworthiness through humor styles: affiliative humor indicates the leader is humble, self-confident and follows an inclusive code of conduct; self-enhancing humor shows the leader's believes in him/herself, maintains a 'glass half-full' approach and has strong moral principles; aggressive humor demonstrates a lack of care about others, the endorsement of manipulative approaches, 
and an attempt to avoid blame; self-defeating humor reveals lack of self-confidence and inability to deal with difficulties and questions the value set of the leader.

Hypothesis 1: Leader a) affiliative and b) self-enhancing humor styles are positively related to trust in the supervisor, while leader c) aggressive and d) self-defeating humor styles are negatively related to trust in the supervisor.

\section{Leader Humor Styles and Subordinates' Self-View}

The impact of humor varies, depending not only on who is using it, but also on who is receiving/observing it (Cooper, 2008). Moreover, although social exchange norms are universal, individual reactions to such norms might differ substantially (Cropanzano \& Mitchell, 2005). This led Nienaber et al. (2015) to call for further research on the role of subordinate attributes in the trust development process.

Subordinates' core self-evaluations (CSE; Judge and Bono, 2001) play a particularly relevant role in the development of trusting relationships (Gardner and Pierce, 2009). CSE represents the fundamental evaluations individuals make about themselves and their behaviors embedded in their environment, and consists of four traits (Judge et al., 2003). Self-esteem refers to the overall value one places on oneself as a person; generalized selfefficacy refers to how well one can perform across situations and contexts; neuroticism is the tendency to focus on negative aspects of the self and use a negative explanatory style; and locus of control focuses on whether the events in one's life are explained by internal or external contingencies (Judge et al., 2003). An individual with a high CSE is characterized by a high self-esteem and self-efficacy, low neuroticism and internal locus of control.

Building on Mayer et al.'s (1995) framework and answering Nienaber et al.'s (2015) call, we propose that employees interpret leader humor styles in light on their CSE as individuals react to events and actions in light of their self-worth (Judge et al., 1997). Individuals with a high CSE will naturally develop trusting relationships with others, as they 
appraise situations more positively (Chang et al., 2012; Neves \& Champion, 2015) and should therefore be less reliant on external cues. In this case, leader humor should not be an important determinant of trust as these individuals are already inclined to develop positive relationships given their high propensity to trust. Individuals with low CSE, however, externalize their negative self-view into the social environment, shaping how they perceive it (Swann, 1992). These individuals not only have difficulties developing trusting relationships but should be more sensitive to information regarding the target of their trust. Subordinates with low CSE should be more attentive to external sources of information and therefore react positively when the leader demonstrates he/she is trustworthy, either by using an affiliative or self-enhancing humor style as 'social lubricants'. Given their low propensity to trust, low CSE individuals should also experience reduced trust when confronted with a supervisor that demonstrates his/her detrimental intentions either by engaging in aggressive or self-defeating humor styles. Thus:

Hypothesis 2: The positive relationship between leader a) affiliative and b) selfenhancing humor styles and trust in the supervisor, and the negative relationship between leader c) aggressive and d) self-defeating humor styles and trust in the supervisor are moderated by CSE, such that these relationships are stronger for low CSE employees Consequences for Employee Behavior

In-role performance and deviant behaviors carry an important, yet independent, weight in performance assessment, and therefore both should be considered (Rotundo \& Sackett, 2002). When individuals are in a social exchange relationship characterized by trust, they strive to repay the positive treatment in kind. Trust leads employees to promote organizational welfare through in-role performance, thereby cementing the establishment of a social exchange relationship with the supervisor (Colquitt et al., 2007; De Jong et al., 2016; Dirks and Ferrin, 2002). Although less frequently examined, trust has also been associated 
with counterproductive work behaviors. Individuals in relationships characterized by a lack of trust also attempt to repay in kind, albeit in a negative fashion, often engaging in voluntary behaviors that violate organizational norms, i.e., organizational deviance (Bennett and Robinson, 2000). The few existing studies have empirically supported this hypothesis (Mo and Shi, 2017; Neves and Champion, 2015).

In light of the norm of reciprocity (Blau, 1964), and given the power of positive humor as a social lubricant and the potential for negative humor to undermine social relationships, particularly for employees with low CSE, we argue that trust in the supervisor is an important mechanism through which leader humor influences employee in-role performance and organizational deviance. Based on the above discussion we propose that, particularly for low CSE employees, trust in the supervisor is an important mechanism through which leader humor influences employee performance and organizational deviance.

Hypothesis 3: The positive relationship between leader a) affiliative and b) selfenhancing humor styles and trust in the supervisor, and the negative relationship between leader c) aggressive and d) self-defeating humor styles and trust in the supervisor are moderated by CSE, such that these relationships are stronger for low CSE employees, with consequences for in-role performance

Hypothesis 4: The positive relationship between leader a) affiliative and b) selfenhancing humor styles and trust in the supervisor, and the negative relationship between leader c) aggressive and d) self-defeating humor styles and trust in the supervisor are moderated by CSE, such that these relationships are stronger for low CSE employees, with consequences for organizational deviance

Our theoretical model is depicted in Figure 1. 


\section{Sample and Procedure}

Our research assistants contacted representatives with managerial responsibilities of several organizations from the services sector operating in Portugal. Representatives of 19 services organizations agreed to participate in the study. We then contacted employees and their supervisors (the number of participants per organization varied depending on availability) in these organizations and only provided the surveys when both parties (employee and supervisor) agreed to participate. The surveys were delivered only on site to guarantee anonymity, since we had to develop a code (combination of letters and numbers) to match employee and supervisor data.

We received surveys from 514 employees and 167 supervisors. After listwise deletion of the participants with missing questions, our final sample was composed by $428(83.3 \%)$ employees and their 151 supervisors (90.4\%). These organizations operated in areas such as real-estate, energy, information technologies, transportation, consultancy, insurance, advertising and health care. The number of participating dyads per organization ranged between 7 and 39, with an average of 23 .

Subordinate demographics were as follows: about half were female (51.4\%), they were on average 37 years old, and had an average organizational tenure of 9.7 years. Their educational attainment was: less than high school 11.4\%; high school 37.4\%; undergraduate degree $39 \%$; master or other graduate diploma $12.1 \%$. Supervisor demographics were as follows: the majority was male $(59.6 \%)$, on average they were 41 years old with a mean organizational tenure of 14.3 years. Their educational attainment was: less than high school 6\%; high school 23.9\%; undergraduate degree $44.4 \%$; master or other post-graduate diploma $29.8 \%$.

\section{Measures}


All the scales were measured through Likert-type scales anchored in $1=$ totally disagree and $5=$ totally agree.

Supervisor humor style. We measured the four types of humor with the Humor Styles Questionnaire (Martin et al., 2003). The scale has 32 items, eight per dimension, which we adapted to focus on the supervisor. Sample items include "My supervisor usually doesn't laugh or joke around much with other people" (R) (Affiliative), "My supervisor's humorous outlook on life keeps him/her from getting overly upset or depressed about things" (Selfenhancing), "If someone makes a mistake, my supervisor will often tease them about it" (Aggressive), and "My supervisor often goes overboard in putting him/herself down when he/she is making jokes or trying to be funny" (Self-defeating). Cronbach's alphas were .86 (Affiliative), .79 (Self-enhancing), .70 (Aggressive), and .76 (Self-defeating).

Core self-evaluations. We measured core self-evaluations with the 12 -item scale developed by Judge et al. (2003). Sample items include “Overall, I am satisfied with myself", "When I try, I generally succeed", “There are times when things look pretty bleak and hopeless to me", and "I determine what will happen in my life". Cronbach's alpha was .77.

Trust in the supervisor. We measured trust in the supervisor with the six items used by Neves and Caetano (2009). These are the highest loading items of the original interpersonal trust scale developed by McAllister (1995). Sample item is "We have a sharing relationship. We can both freely share our ideas, feelings, and hopes". Cronbach's alpha was .81 .

In-role performance. Supervisors rated their subordinates' in-role performance with the 5 items developed by Williams and Anderson (1991). Sample item is "This employee adequately completes assigned duties". Cronbach's alpha was .85.

Organizational deviance. Supervisors responded to the five items previously used by Neves and Champion (2015), which were adapted from Aquino et al. (1999) and Robinson 
and Bennett's (1995) scales. Sample item includes “This employee intentionally slowed down the pace of his/her work". Cronbach's alpha was .82.

Control variables. We examined employees' and supervisors' age, gender, education, length of relationship, and tenure in the organization. We followed Becker et al.'s (2016) recommendation that models should only include control variables that are statistically related to the outcome variables. Of the demographic variables assessed, only employees' gender, education, and their tenure with supervisor; and supervisors' gender and education were significantly related to at least one of our outcome variables, and thus were kept in our analyses. We also included trust in the organization (7-item scale developed by Robinson, 1996) as a control mechanism. This allows us to examine whether the key mechanism is trust in the supervisor or just trust in general, regardless of the agent.

\section{RESULTS}

Descriptive statistics, reliabilities, and zero-order correlations are presented in Table 1. Before testing our hypotheses, we assess the distinctiveness of the constructs with Confirmatory Factor Analysis (CFA). Given that the ratio between the number of indicators $(\mathrm{k}=67)$ and the sample size $(\mathrm{N}=428)$, we used a partial disaggregation technique (Bagozzi \& Edwards, 1998). This technique consists of reducing the number of indicators by combining two or more items into one single indicator. We combined high- and low-loading items, as recommended by Little, Cunningham, Shahar, and Widaman (2002), for the scales with the highest number of items (CSE and humor), reducing them to four indicators each. Table 1 here

We compared our theoretical model (including the control mechanism), composed of nine constructs, to a series of nested models using the chi-square difference test (Bentler \& Bonett, 1980). The nine-factor model presented a good fit to the data $\left(\chi^{2}=1554.91, \mathrm{df}=824\right.$, $\mathrm{CFI}=.91, \mathrm{RMSEA}=.05, \mathrm{SRMR}=.06)$. This model presented a significantly better fit than 
five nested models, and therefore we treated the nine constructs separately in our analyses. All indicators presented acceptable loadings, with standardized coefficients ranging between .76 to .80 for affiliative humor, .61 to .77 for self-enhancing humor, .59 to .73 for selfdefeating humor, .51 to .65 for aggressive humor, .69 to .73 for CSE, .61 to .72 for trust in the supervisor, .42 to .73 for trust in the organization, .26 to .90 for in-role performance, and .53 to .84 for organizational deviance.

\section{Hypothesis Testing}

Because our data had a multilevel structure such that subordinates (Level 1) were nested in supervisors (Level 2) who were nested in organizations (Level 3), we employed hierarchical linear modeling (HLM). As such, we controlled for the random level 2 and level 3 variance in the intercept and tested all hypotheses using HLM3 (Raudenbush et al., 2013). All continuous variables were grand mean centered.

Following the recommendations of Becker et al. (2016) all models were tested with and without control variables. We did not find substantive differences and for completeness of information we report findings with control variables.

As shown in Table 2, affiliative humor $(\gamma=.31, p<.01)$ and self-enhancing humor $(\gamma$ $=.26, p<.01)$ were positively, while self-defeating humor $(\gamma=-.10, p<.05)$ and aggressive humor $(\gamma=-.42, p<.01)$ were negatively, associated with trust in the supervisor. These findings support hypotheses 1a to $1 \mathrm{~d}$.

Table 2 here

The beneficial leader humor styles and CSE interaction effects on trust in the supervisor were significant, but not the detrimental humor and CSE interaction effects (affiliative humor: $\gamma=-.23, p<.01$; self-enhancing humor: $\gamma=-.20, p<.01$; self-defeating humor: $\gamma=.04, n s$; aggressive humor: $\gamma=.01, n s)$. We probed the nature of the significant interaction effects using the procedure recommended by Cohen et al. (2003; see Figure 2) for 
low (-1 standard deviation, SD) and high (+1 SD) CSE. For low CSE the positive relationship of affiliative humor with trust in the supervisor was stronger $(\mathrm{B}=.42, \mathrm{SE}=.05, p<.01)$ than for high CSE $(\mathrm{B}=.18, \mathrm{SE}=.06, p<.05)$. A similar pattern of relationships was observed for the self-enhancing humor $\mathrm{x}$ CSE interaction: the relationship of self-enhancing humor with trust in the supervisor was stronger for low CSE than for high CSE $(\mathrm{B}=.39, \mathrm{SE}=.08, p<$ $.01 ; \mathrm{B}=.17, \mathrm{SE}=.07, p<.01)$. Thus, hypotheses $2 \mathrm{a}$ and $2 \mathrm{~b}$ are supported, but not $2 \mathrm{c}$ and $2 \mathrm{~d}$. Figure 2 here

We then tested the moderated mediation effect using the Monte Carlo Method of Assessing Mediation (MCMAM) (Selig and Preacher, 2008) since it is suited for multilevel models and show comparable performance to bootstrapping (Bauer et al., 2006).

The indirect effects of affiliative humor for both low and high CSE were significant ($1 \mathrm{SD}=.06, \mathrm{CI}=.005, .11 ;+1 \mathrm{SD}=.02, \mathrm{CI}=.002, .05)$. Likewise, the indirect effects for self-enhancing humor was significant for both low $(-1 \mathrm{SD}=.05, \mathrm{CI}=.005, .11)$ and high $\mathrm{CSE}(+1 \mathrm{SD}=.02, \mathrm{CI}=.0007, .06)$. Both moderated mediation indexes were significant (affiliative humor x CSE: -.03, CI = -.07, -.003; self-enhancing humor x CSE: -. 03, CI = $.06,-.0004)$, suggesting that the magnitudes of these indirect effects were different across low and high CSE. Thus, hypotheses $3 \mathrm{a}$ and $3 \mathrm{~b}$ are supported. On the other hand, aggressive humor was indirectly related to subordinates' in-role performance independently of CSE (indirect effect: - $.05, \mathrm{CI}=-.11,-.01$ ), whereas self-defeating humor was not (indirect effect: $.01, \mathrm{CI}=-.03, .00)$.

Trust in the supervisor $\left(\gamma_{800}=-.11, \mathrm{~ns}\right)$ did not predict organizational deviance. Thus, hypothesis 4 was not supported. Nonetheless, self-enhancing leader humor held negative $(\gamma=$ $-.16, p<.05)$, whereas self-defeating leader humor presented positive $(\gamma=.12, p<.05)$, direct effects on organizational deviance.

\section{DISCUSSION}


The study of humor in the workplace is still nascent, particularly if focused on leaders. While not all leaders use humor (or use it for positive goals), some do incorporate it in their repertoire. However, and as our study shows, different leader humor styles carry rather distinct consequences for employee behavior.

Our findings contribute to the literatures on trust and humor in several ways. First, grounded in social exchange theory and building on the trustworthiness framework (Mayer et al., 1995), we extend prior theorizations (Goswami et al., 2016; Kim et al., 2016) and show how leader humor helps establish/destroy trust in the supervisor. This demonstrates the potential of humor as a management tool and as a barrier for trust, depending on its style.

Second, our findings also suggest that leader affiliative and self-enhancing humor styles are particularly helpful for employees with a negative self-view. This is aligned with the perspective that the receiver is an important part of humor effectiveness (Cooper, 2008). Prior research showed the importance of CSE for the development of trust (Gardner and Pierce, 2009), but did not provide strategies to help those with low CSE. Leader affiliative and self-enhancing humor styles offer a potential answer.

Third, our study is part of an emerging literature that shows that leader humor has an impact - beneficial or detrimental - on employee behavior. This nuanced view of humor contrasts with the most common approach that tends to treat humor as an overall positive construct (Mesmer-Magnus et al., 2012) and provides further evidence that processes should be considered when examining the link between humor and behavior (Cooper, 2008). This is particularly important in the organizational context given the potential costs of aggressive and self-defeating leader humor styles for performance and deviance. The lack of significant interaction effects for both aggressive and self-defeating leader humor styles and employee CSE suggest that the use of negative humor by leaders is detrimental to all employees and as such should be the focus of organizational interventions. 
The present findings suggest that training (prospective) leaders, on the use of humor, particularly on the distinction between beneficial and detrimental humor may be helpful. The potential of beneficial humor styles (affiliative and self-enhancing) as a management tool has already inspired top business schools to develop specific courses on the use of humor (Stanford's course 'Humor: Serious Business' is a good example).

Organizations should also attempt to develop a culture of beneficial humor. There are several companies operating in rather diverse sectors famous for their cultures of fun, such as Southwest Airlines or Zappos. The development and maintenance of such cultures starts in the selection process, where newcomers are hired based on cultural fit, rather than functional competencies alone. These organizations often internally promote individuals to leadership positions, so being embedded in the culture should reflect itself in leader behavior.

\section{Limitations and Future Research}

Our study is not without limitations. Our cross-sectional design does not allow for causality inferences, and therefore the possibility that the process is bidirectional or even in the opposite direction cannot be excluded. However, a significant body of research has broadly supported the leadership perceptions - employee attitudes - employee behavior process model (for meta-analytical evidence see Lee et al., 2018; $\mathrm{Ng}, 2017$ ). The present model should nonetheless be tested using experimental or cross-lagged panel designs.

Second, this study also raises concerns about common method variance (CMV). However, there are several factors that minimize such concerns. First, and as argued by Spector (2006), it is difficult to accurately assess internal states, such as perceptions, attitudes or emotions with other sources beyond self-report. Second, CMV deflates interaction effects, making their detection more difficult (Busemeyer \& Jones, 1983). Third, we obtained measures of predictor and criterion variables from different sources and balanced positive and 
negative items in our measures as recommended by Podsakoff et al. (2012). Fourth, the CFA supported the distinctiveness of the measures collected.

Future research should consider other potential mechanisms of the effects of leader humor styles. For example, the broaden-and-build theory (Fredrickson, 1998) posits that positive emotions broaden the individual's thought-action repertoire, which helps build personal resources. Future research may also consider cultural differences and similarities concerning the use and expression of humor. Is leader humor dependent on the different cultural expectations concerning what effective leaders do?

\section{CONCLUSION}

Our study provides empirical evidence for the importance of leader humor styles for employee behavior: if used in a beneficial fashion, it helps develop trusting relationships, particularly for those that normally would have difficulties in establishing such relationships; if used poorly, it destroys the trust employees place in their leaders, with consequences for performance and deviance. So it seems that, as Beard (2014) has described in rather simple terms, "the workplace needs laughter" (p. 130) and probably leadership is a good place to start, as long as the differences between humor styles are taken into account. 


\section{References}

Aquino, K., Lewis, M.U., and Bradfield, M. (1999), "Justice constructs, negative affectivity, and employee deviance: A proposed model and empirical test", Journal of Organizational Behavior, Vol. 20 No. 7, pp. 1073-1091.

Avolio, B.J., Howell, J.M., and Sosik, J.J. (1999), “A funny thing happened on the way to the bottom line: Humor as a moderator of leadership style effects", Academy of Management Journal, Vol. 42 No. 2, pp. 219-227.

Bagozzi, R. P., and Edwards, J. R. (1998), “A general approach for representing constructs in organizational research", Organizational Research Methods, Vol. 1, pp. 45-87.

Bauer, D.J., Preacher, K.J., and Gil, K.M. (2006), “Conceptualizing and testing random indirect effects and moderated mediation in multilevel models: New procedures and recommendations", Psychological Methods, Vol. 11 No. 2, pp. 142-163.

Beard, A. (2014), "Leading with humor”, Harvard Business Review, Vol. 92 No. 5, 130-131.

Becker, T.E., Atinc, G., Breaugh, J.A., Carlson, K.D., Edwards, J.R., and Spector, P.E. (2016), "Statistical control in correlational studies: 10 essential recommendations for organizational researchers", Journal of Organizational Behavior, Vol. 37 No. 2, pp. 157-167.

Bennett, R. J., and Robinson, S. L. (2000), “Development of a measure of workplace deviance", Journal of Applied Psychology, Vol. 85 No. 3, pp. 349-360.

Bentler, P. M., and Bonett, D. G. (1980), "Significance tests and goodness of fit in the analysis of covariance structures", Psychological Bulletin, Vol. 88, pp. 588-606.

Blau, P. (1964), Exchange and power in social life, Wiley, New York, NY.

Busemeyer, J.R., and Jones, L.E. (1983), “Analysis of multiplicative combination rules when the causal variables are measured with error", Psychological Bulletin, Vol. 93 No. 3, pp. 549-562. 
Chang, C., Ferris, D.L., Johnson, R.E., Rosen, C.C., and Tan, J.A. (2012), “Core SelfEvaluations: A Review and Evaluation of the Literature”, Journal of Management, Vol. 38 No. 1 , pp. $81-128$

Cohen, J., Cohen, P., West, S.G., and Aiken, L.S. (2003), Applied multiple regression/correlation analysis for the behavioral sciences (3rd ed.), Lawrence Erlbaum Associates Publishers, Mahwah, NJ.

Colquitt, J. A., Scott, B. A., and LePine, J. A. 2007, “Trust, trustworthiness, and trust propensity: A meta-analytic test of their unique relationships with risk taking and job performance", Journal of Applied Psychology, Vol. 92 No. 4, pp. 909-927.

Cooper, C. D. (2008), "Elucidating the bonds of workplace humor: A relational process model", Human Relations, Vol. 61 No. 8, 1087-1115.

Cropanzano, R., and Mitchell, M.S. (2005), "Social exchange theory: An interdisciplinary review”, Journal of Management, Vol. 31 No. 6, pp. 874-900.

De Jong, B.A., Dirks, K.T., and Gillespie, N. (2016), “Trust and team performance: A metaanalysis of main effects, moderators, and covariates", Journal of Applied Psychology, Vol. 101 No. 8, pp. 1134-1150.

Dirks, K.T., and Ferrin, D.L. (2002), “Trust in leadership: Meta-analytic findings and implications for research and practice", Journal of Applied Psychology, Vol. 87 No. 4, pp. 611-628.

Fredrickson, B.L. (1998), “What good are positive emotions?”, Review of General Psychology, Vol. 2 No. 3, pp. 300-319.

Gardner, D.G., and Pierce, J.L. (2009), “The core self-evaluation scale: Further construct validation evidence”, Educational and Psychological Measurement, Vol. 70 No. 2, pp. 291-304. 
Gkorezis, P., and Bellou, V. (2016), “The relationship between leader self-deprecating humor and perceived effectiveness: Trust in leader as a mediator", Leadership \& Organization Development Journal, Vol. 37 No. 7, pp. 882-898.

Goswami, A., Nair, P., Beehr, T., and Grossenbacher, M. (2016), “The relationship of leaders' humor and employees' work engagement mediated by positive emotions: Moderating effect of leaders' transformational leadership style”, Leadership \& Organizational Development Journal, Vol. 37 No. 8, pp. 1083-1099.

Huo, Y., Lam, W., and Chen, Z. (2012), “Am I the only one this supervisor is laughing at? Effects of aggressive humor on employee strain and addictive behaviors". Personnel Psychology, Vol. 65 No. 4, pp. 859-885.

Judge, T. A., and Bono, J. E. (2001), "Relationship of core self-evaluations traits - selfesteem, generalized self-efficacy, locus of control, and emotional stability - with job satisfaction and job performance: A meta-analysis", Journal of Applied Psychology, Vol. 86 No. 1, pp. 80-92.

Judge, T. A., Erez, A., Bono, J. E., and Thoresen, C. J. (2003), “The Core Self-Evaluations Scale (CSES): Development of a measure", Personnel Psychology, Vol. 56 No. 2, pp. 303-331.

Judge, T.A., Locke, E.A., and Durham, C.C. (1997), “The dispositional causes of job satisfaction: A core evaluations approach", Research in Organizational Behavior, Vol. 19, pp. 151-188.

Karakowsky, L., Podolsky, M., and Elangovan, A.R. (2019), "Signaling trustworthiness: The effect of leader humor on feedback-seeking behavior", The Journal of Social Psychology, Advance online publication 
Kim, T., Lee, D., and Wong, N.Y.S. (2016), "Supervisor humor and employee outcomes: The role of social distance and affective trust in supervisor", Journal of Business and Psychology, Vol. 31 No. 1, pp. 125-139.

Lee, A., Willis, S., and Tian, A. W. (2018), “Empowering leadership: A meta-analytic examination of incremental contribution, mediation, and moderation", Journal of Organizational Behavior, Vol. 39 No. 3, pp. 306-325.

Little, T. D., Cunningham, W. A., Shahar, G., and Widaman, K. F. (2002), “To parcel or not to parcel: Exploring the question, weighing the merits", Structural Equation Modeling, Vol. 9, pp. 151-173.

Martin, R.A., Puhlik-Doris, P., Larsen, G., Gray, J., and Weir, K. (2003), “Individual differences in uses of humor and their relation to psychological well-being: Development of the Humor Styles Questionnaire”, Journal of Research in Personality, Vol. 37 No. 1, pp. 48-75.

Mayer, R.C., Davis, J.H. and Schoorman, F.D. (1995), “An integrative model of organizational trust”, The Academy of Management Review, Vol. 20 No. 3, pp. 709734.

McAllister, D.J. (1995), “Affect- and cognition-based trust as foundations for interpersonal cooperation in organizations", Academy of Management Journal, Vol. 38 No. 1, pp. 2459.

Mesmer-Magnus, J., Glew, D.J., and Viswesvaran, C. (2012), “A meta-analysis of positive humor in the workplace", Journal of Managerial Psychology, Vol. 27 No. 2, pp. 155190.

Mo, S., and Shi, J. (2017), "Linking ethical leadership to employee burnout, workplace deviance and performance: Testing the mediating roles of trust in leader and surface acting”, Journal of Business Ethics, Vol. 144 No. 2, pp. 293-303. 
Neves, P. and Caetano, A. (2009), "Commitment to change: Contributions to trust in the supervisor and work outcomes", Group and Organization Management, Vol. 34 No.6, pp. 623-644.

Neves, P., and Champion, S. (2015), “Core self-evaluations and workplace deviance: The role of resources and self-regulation”, European Management Journal, Vol. 33 No. 5, pp. 381-391.

Nienaber, A., Romeike, P.D., Searle, R., and Schewe, G. (2015), “A qualitative meta-analysis of trust in supervisor-subordinate relationships, Journal of Managerial Psychology, Vol. 30 No. 5, pp. 507-534.

Ng, T. W.H. (2017), “Transformational leadership and performance outcomes: Analyses of multiple mediation pathways", The Leadership Quarterly, Vol. 28 No.3, pp. 385-417.

Podsakoff, P.M., MacKenzie, S.B., and Podsakoff, N.P. (2012), “Sources of method bias in social science research and recommendations on how to control it", Annual Review of Psychology, Vol. 63, pp 539-569.

Pundt, A. (2015), “The relationship between humorous leadership and innovative behavior”, Journal of Managerial Psychology, Vol. 30 No. 8, pp. 878-893.

Pundt, A., and Herrmann, F. (2015), “Affiliative and aggressive humour in leadership and their relationship to leader-member exchange", Journal of Occupational and Organizational Psychology, Vol. 88 No. 1, pp. 108-125.

Pundt, A., and Venz, L. (2017), "Personal need for structure as a boundary condition for humor in leadership", Journal of Organizational Behavior, Vol. 38 No. 1, pp. 87-107.

Raudenbush, S.W., Bryk, A.S., and Congdon, R. (2013), “HLM 7.01 for Windows”, Scientific Software International Inc, Skokie, IL. 
Robert, C., Dunne, T.C., and Iun, J. (2016), “The impact of leader humor on subordinate job satisfaction: The crucial role of leader-subordinate relationship quality", Group \& Organization Management, Vol. 41 No. 3, pp. 375-406.

Robert, C. and Yan, W. (2007), "The case for developing new research on humor and culture in organizations: Toward a higher grade of manure", Research in Personnel and Human Resources Management, Vol. 26, pp. 205-267.

Robinson, S.L. (1996), "Trust and the breach of the psychological contract", Administrative Science Quarterly, Vol. 41 No. 4, pp. 574-599.

Robinson, S. L., and Bennett, R. J. (1995), “A typology of deviant workplace behaviors: A multidimensional scaling study", Academy of Management Journal, Vol. 38 No. 2, pp. $555-572$.

Romero, E.J., and Cruthirds, K.W. (2006), "The use of humor in the workplace”, Academy of Management Perspectives”, Vol. 20 No. 2, pp. 58-69.

Rotundo, M., and Scakett, P.R. (2002), “The relative importance of task, citizenship, and counterproductive performance to global ratings of job performance: A policycapturing approach”, Vol. 87 No. 1, pp. 66-80.

Selig, J.P., and Preacher, K.J. (2008), "Monte Carlo method for assessing mediation: An interactive tool for creating confidence intervals for indirect effects", available at http://quantpsy.org/medmc/medmc.htm (accessed 2 January 2019).

Schoorman, F.D., Mayer, R.C., and Davis, J.H. (2007), “An integrative model of organizational trust: Past, present, and future", Academy of Management Review, Vol. 32 No. 2, pp. 344-354.

Spector, P. E. (2006), “Method variance in organizational research: Truth or urban legend?”, Organizational Research Methods, Vol. 9 No. 2, pp. 221-232. 
Swann, W.B., Jr. (1992), “Seeking 'truth', finding despair: Some unhappy consequences of a negative self-concept", Current Directions in Psychological Science, Vol. 1 No. 1, pp. $15-18$.

Tremblay, M. (2017), "Humor in teams: Multilevel relationships between humor climate, inclusion, trust, and citizenship behaviors", Journal of Business and Psychology, Vol. 32 No. 4, pp. 363-378.

Williams, L. J., and Anderson, S. E. (1991), "Job satisfaction and organizational commitment as predictors of organizational citizenship and in-role behaviors", Journal of Management, Vol. 17 No. 3, pp. 601-617.

Wisse, B., and Rietzschel, E. (2014), "Humor in leader-follower relationships: Humor styles, similarity and relationship quality", Humor, Vol. 27 No. 2, pp. 249-269. 
Table 1

Correlations, means, standard deviations and reliabilities

\begin{tabular}{|c|c|c|c|c|c|c|c|c|c|c|c|c|c|c|c|}
\hline & Mean & S.D. & 1 & 2 & 3 & 4 & 5 & 6 & 7 & 8 & 9 & 10 & 11 & 12 & 13 \\
\hline 1. Affiliative humor & 3.58 & .73 & $(.85)$ & & & & & & & & & & & & \\
\hline 2. Self-enhancing humor & 3.05 & .61 & $.63 * *$ & $(.79)$ & & & & & & & & & & & \\
\hline 3. Aggressive humor & 2.61 & .65 & $-.10^{*}$ & $-.29 * *$ & $(.68)$ & & & & & & & & & & \\
\hline 4. Self-defeating & 2.18 & .64 & $-.12 *$ & $.12 *$ & $.34 * *$ & $(.76)$ & & & & & & & & & \\
\hline 5. CSE & 3.99 & .53 & $.14 * *$ & $.14 * *$ & $-.34 * *$ & $-.25 * *$ & $(.77)$ & & & & & & & & \\
\hline 6. Trust in the supervisor & 3.97 & .73 & $.48 * *$ & $.51 * *$ & $-.50 * *$ & $-.18 * *$ & $.33 * *$ & $(.82)$ & & & & & & & \\
\hline 7. Trust in the organization & 3.90 & .71 & $.20 * *$ & $.25 * *$ & $-.40 * *$ & $-.25 * *$ & $.51 * *$ & $.49 * *$ & $(.81)$ & & & & & & \\
\hline 8. In-role performance & 3.81 & .69 & $.16^{* *}$ & $.22 * *$ & $-.15^{* *}$ & $-.12 *$ & $.20 * *$ & $.26^{* *}$ & $.14 * *$ & $(.83)$ & & & & & \\
\hline 9. Organizational deviance & 1.65 & .76 & $-.11^{*}$ & $-.12 *$ & $.12 *$ & .09 & $-.19 * *$ & $-.17 * *$ & -.09 & $-.41 * *$ & $(.82)$ & & & & \\
\hline 10. Subordinate's gender & 1.51 & .50 & -.02 & -.04 & .03 & -.03 & -.03 & -.03 & $-.11 *$ & .01 & .02 & - & & & \\
\hline 11. Subordinate's education & 3.48 & .93 & .07 & -.00 & -.09 & -.09 & $.18^{* *}$ & .05 & .08 & $.16^{* *}$ & $-.15^{* *}$ & -.03 & - & & \\
\hline 12. Subordinate's WG Tenure & 5.42 & 5.85 & -.00 & -.01 & .03 & $-.12 *$ & .06 & $.11 *$ & .04 & .08 & -.03 & .09 & $-19 * *$ & - & \\
\hline 13. Supervisor's gender & 1.40 & .49 & -.00 & .00 & .04 & .03 & -.03 & -.04 & $-.11 *$ & -.04 & .01 & $.32 * *$ & -.07 & -.03 & - \\
\hline 14. Supervisor's education & 3.96 & .92 & .04 & -.00 & .08 & -.03 & .12 & .03 & $.10^{*}$ & .08 & -.01 & -.06 & $.39 * *$ & -.08 & .08 \\
\hline
\end{tabular}

Notes. Education was coded as follows: $: 1=4^{\text {th }}$ grade $; 2=9^{\text {th }}$ grade $; 3=$ complete high school $; 4=$ undergraduate $; 5=$ postgraduate studies

Gender coding: $1=$ male, $2=$ female. $W G=$ work group $* p<.05, * * p<.01$. Level $1 N=428$, Level 2 N=151, Level $3=1$ 
Table 2

HLM results for trust in the supervisor, in-role performance and organizational deviance

\begin{tabular}{|c|c|c|c|c|c|c|c|}
\hline & Model 1: & Model 2: & Model 3: Self- & Model 4: & Model 5: Self- & & Model 7: \\
\hline & Main & Affiliative & Enhancing & Aggressive Humor & Defeating Humor & Model 6: In-role & Organizational \\
\hline & effects & Humor x CSE & Humor x CSE & $x$ CSE & x CSE & Performance & Deviance \\
\hline Intercept $\left(\gamma_{000}\right)$ & $4.01(.11)^{* *}$ & $4.01(.11)^{* *}$ & $4.02(.11)^{* *}$ & $4.01(.11)^{* *}$ & $4.02(.11)^{* *}$ & $3.84(.14)^{* *}$ & $1.54(.17)^{* *}$ \\
\hline \multicolumn{8}{|l|}{ Controls } \\
\hline Supervisor's education & $.05(.04)$ & $.04(.04)$ & $.04(.04)$ & $.04(.04)$ & $.04(.04)$ & $.04(.05)$ & $.07(.06)$ \\
\hline Supervisor's Sex & $-.04(.06)$ & $-.04(.06)$ & $-.05(.06)$ & $-.04(.06)$ & $-.04(.06)$ & $-.06(.08)$ & $.02(.10)$ \\
\hline Subordinate's Sex & $-.01(.06)$ & $-.01(.05)$ & $.02(.05)$ & $.01(.05)$ & $.01(.05)$ & $.03(.07)$ & $.05(.07)$ \\
\hline Subordinate's Education & $-.01(.03)$ & $-.01(.03)$ & $-.02(.03)$ & $-.02(.03)$ & $-.02(.03)$ & $.08(.04)$ & $-.11(.04)^{* *}$ \\
\hline Tenure with supervisor & $.01(.00)^{*}$ & $.01(.00)^{*}$ & $.01(.00)^{*}$ & $.01(.00)^{*}$ & $.01(.00)^{*}$ & $.01(.01)$ & $-.00(.01)$ \\
\hline Trust in the organization & & & & & & $-.02(.05)$ & $.02(.05)$ \\
\hline \multicolumn{8}{|l|}{ Independent variables } \\
\hline Affiliative humor & $.31(.05)^{* *}$ & $.30(.05)^{* *}$ & $.30(.05)^{* *}$ & $.30(.05)^{* *}$ & $.30(.05)^{* *}$ & $-.03(.06)$ & $.05(.06)$ \\
\hline Self-enhancing humor & $.26(.06)^{* *}$ & $.28(.06)^{* *}$ & $.28(.06)^{* *}$ & $.26(.06)^{* *}$ & $.26(.06)^{* *}$ & $.20(.07)^{* *}$ & $-.16(.07)^{*}$ \\
\hline
\end{tabular}


Self-defeating humor

Aggressive Humor

CSE

Interaction

Mediator

Trust in the supervisor

$\begin{array}{lllll}-.10(.04)^{*} & -.08(.04)^{\dagger} & -.09(.04)^{*} & -.08(.04)^{\dagger} & -.08(.04)^{\dagger} \\ -.42(.05)^{* *} & -.37(.05)^{* *} & -.37(.05)^{* *} & -.39(.05)^{* *} & -.41(.04)^{* *} \\ & .15(.05)^{* *} & .15(.05)^{* *} & .16(.05)^{* *} & .16(.05)^{* *} \\ & -.23(.06)^{* *} & -.20(.08)^{*} & .01(.07) & .04(.08)\end{array}$

$.13(.06)^{*}$ $-.11(.06)^{\dagger}$

$* * p<.01, * p<.05,{ }^{\dagger} p<.10$ 

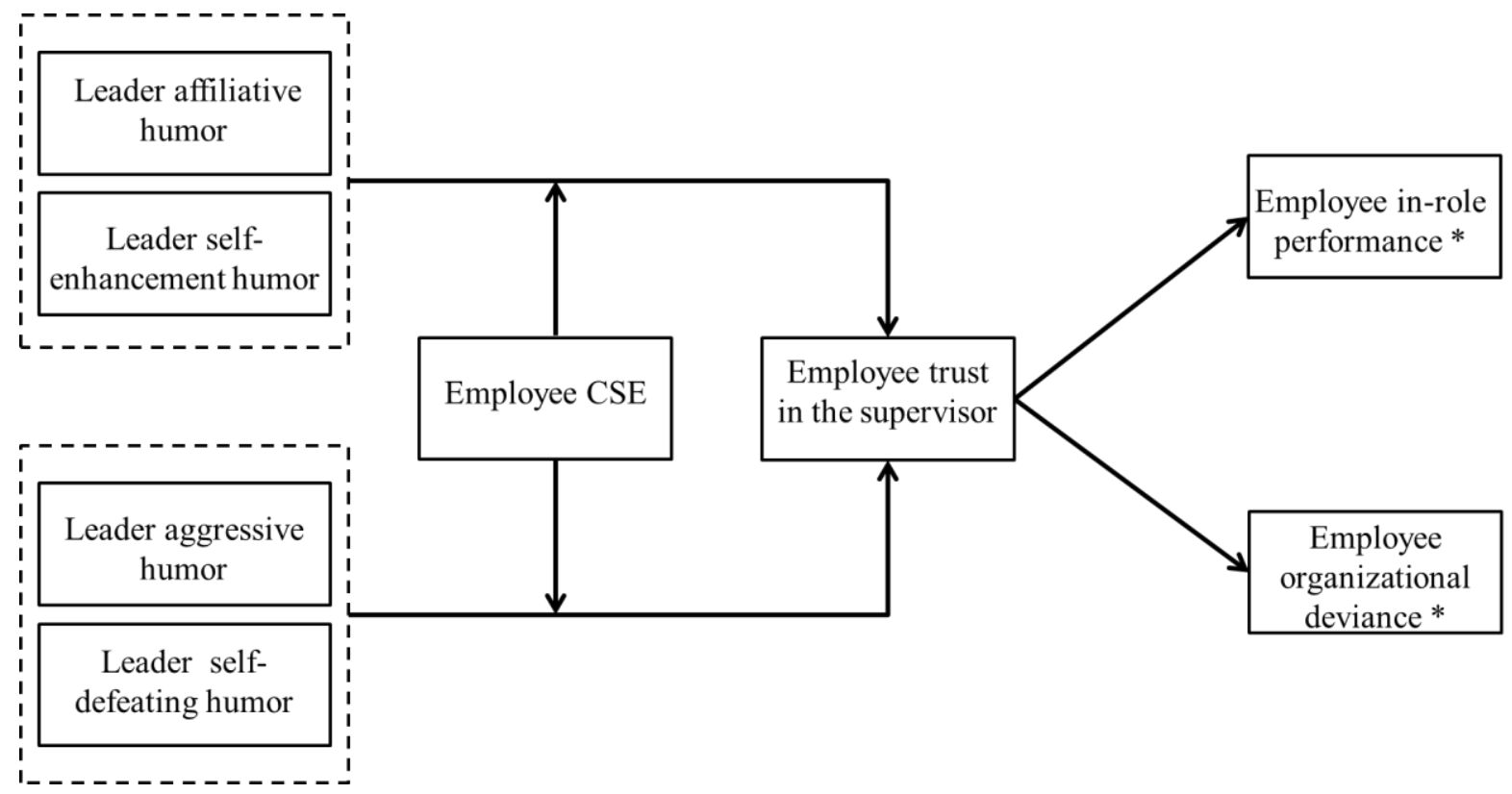

Figure 1. Theoretical model

Note. ${ }^{*}$ measured by the supervisor 


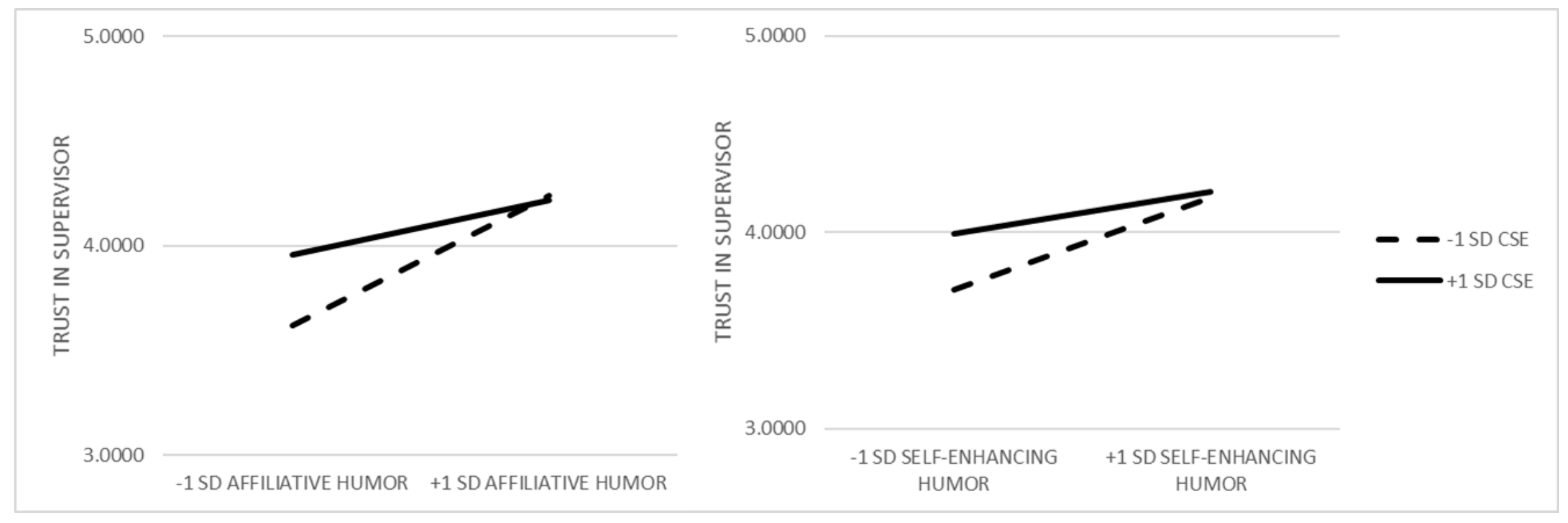

Figure 2. Interaction effects on trust in the supervisor 